\title{
MOLDURA E HORIZONTALIDADE NA PRIMEIRA MISSA NO BRASIL
}

\author{
Mário César Coelho \\ Professor do Departamento de Expressão Gráfica/UFSC
}

\section{Resumo}

Este artigo aborda as diferenças de linguagens entre duas formas de pintura executadas por Victor Meirelles, a Primeira Missa no Brasil em 1860 e o Panorama do Descobrimento do Brasil exposto em 1900. Os Panoramas eram pinturas expostas numa arquitetura especial chamada de rotundas e tiveram seu auge no século XIX. Enquanto o Panorama parece não ter limites numa circularidade horizontal, na pintura tradicional o espaço é delimitado pelas bordas do quadro. Além disso, no caso da Primeira Missa no Brasil, algumas reproduções colocam em evidência apenas o detalhe da cena central.

Palavras-chave: Victor Meirelles. Primeira Missa no Brasil. Panorama.

Frame and Horizontalidade in the Primeira Missa no Brasil

\begin{abstract}
This article approachs the difference of languages between two kinds of painting of Victor Meirelles, a Primeira Missa no Brasil in 1860 and Panorama do Descobrimento do Brasil exposed in 1900. The Panoramas was paintings exposed at especial architecture called rotundas and they had they peak in $19^{\text {th }}$ century. While the Panorama seems no limits at horizontal circularity, at traditional painting the space is delimited by the edge of frame. In the case of Primeira Missa no Brasil beside some reproductions put in evidence just the detail of central scene.
\end{abstract}

Key words: Victor Meirelles. Primeira Missa no Brasil. Panorama. 
Victor Meirelles de Lima (1832-1903) pintou o Panorama do Descobrimento do Brasil (1900) inspirado em outra obra realizada quarenta anos antes e considerada sua obra prima maior. A Primeira Missa no Brasil (1860) foi seu lançamento no mundo da Academia e fazer uma versão da obra como um Panorama foi como uma tradução de linguagens no mundo da pintura. Da cultura do museu à cultura do espetáculo, de um público que freqüentava as Exposições da Academia ao anônimo da multidão, realizar este Panorama pode ser visto como uma tentativa derradeira de reavivar sua trajetória artística.

Os Panoramas eram pinturas imensas expostas em rotundas nos centros de grandes cidades no século XIX (esta forma de pintura foi patenteada em 1787 por Robert Barker). Victor Meirelles pintou três Panoramas, hoje todos perdidos, e dos quais restam apenas os Estudos no acervo do Museu Nacional de Belas Artes do Rio de Janeiro. O Panorama do Descobrimento do Brasil foi seu terceiro e último Panorama.

Quando a Primeira Missa no Brasil foi exposta em 1861, foi dito: “(...) cá o nosso Meirelles ou menos prudente ou mais ousado, não pôs a mínima dúvida em medir-se desde logo com todas as grandes dificuldades da arte, começando por onde os outros acabam (...) ${ }^{1}$

A Primeira Missa no Brasil foi a primeira grande obra de Meirelles, uma obra-prima do gênero histórico que inaugurou um novo formato visual e narrativo, influenciando e estabelecendo um padrão visual para outros pintores. ${ }^{2}$

Victor Meirelles pintou a Primeira Missa no Brasil (1860) em Paris, utilizando como referência a Carta do escrivão Pêro Vaz de Caminha, um relato de viagem. A pintura acabou se tornando um documento visual que se transformou num paradigma da pintura histórica nacional. Ela oferecia a viagem no tempo, à possibilidade da verdade dos fatos, inaugurando os diversos retratos históricos da nação. ${ }^{3}$ Meirelles recebeu sugestões para a composição, entre elas, de acrescentar as caravelas para contextualizar o tema e dar maior vigor ao fato histórico, apesar de que, como escreveu Jorge Coli "a descoberta do Brasil foi uma invenção do século XIX" ${ }^{4}$. Os historiadores, no decorrer do século XIX e XX, "investiram a obra da autoridade histórica da verdade" ${ }^{5}$. Quatro décadas depois, Victor Meirelles retornaria ao seu tema inicial, possibilitando uma oportunidade de pensar-se nas peculiaridades destas duas formas de fazer artístico. Por meio das semelhanças e diferenças pode-se fazer uma comparação das obras pintadas com a mesma temática em tempos distintos, uma em 1860 e a outra em 1900.

Apesar de ambas serem pinturas, elas diferem na forma de exposição. Uma plana e de formato acadêmico tradicional, ocupa as paredes do Museu Nacional de Belas Artes do Rio de Janeiro, e perdura até hoje como uma das obras fundadoras da pintura brasileira. A outra, o Panorama do Descobrimento 
do Brasil, era uma imensa pintura circular nas paredes envolventes de uma rotunda, ligada à cultura do espetáculo. Desapareceria para sempre, deixando como registro visual apenas seus pequenos Estudos. Por outro lado, a pintura panorâmica e a pintura de cavalete conferem dois padrões diferentes de recepção à obra. Uma com valor de culto, pautada nos valores estéticos da contemplação em silêncio de uma obra no museu, a outra, freqüentada por multidões dos centros das cidades, num espetáculo de caráter híbrido, envolvendo arquitetura, pintura, teatro, escultura. No Panorama "não era mais uma relação frontal com um objeto externo, mas uma identificação perceptiva requerendo uma participação sensorial totalizante" ${ }^{6}$.

No Panorama pintado em 1900, existe uma visão circundante de 360 graus delimitada apenas pelo teto, piso e os contornos de uma plataforma. Os limites são, portanto tridimensionais, a arquitetura faz parte da moldura. Isto é muito importante para diferenciar a pintura tradicional da pintura panorâmica: a delimitação do espaço da pintura. Os museus se adequam às pinturas de grandes dimensões como Batalha do Avaí e Batalha dos Guararapes, mas os Panoramas Circulares necessitavam de um espaço ainda mais especial, envolvente e com grande altura, condições impossíveis de serem obtidos num prédio que não fosse projetado para tal finalidade. Enquanto o Panorama parece não ter limites, se estendendo numa circularidade horizontal, na pintura tradicional o espaço da pintura é delimitado pelas bordas do quadro ${ }^{7}$. A pintura com moldura configura a obra com valor de mercado, significando dizer que "a imagem está à venda e se destina a ser levada" . Esta é uma diferença fundamental, a mobilidade das obras e a adaptação a um mercado de artes. Muitas das telas panorâmicas que chegaram até os dias de hoje, somente sobreviveram porque foram retalhadas facilitando a comercialização.

A pintura pendurada na parede é como uma ilha no mundo". Se na moldura convencional configura-se um dentro e um fora, separando "mundo real" e pintura, no Panorama justamente a intenção é de que esta relação seja ambígua, a pintura necessita fazer parte da própria arquitetura onde o espectador está inserido. O tema da moldura merece esta abordagem, pois na rotunda ela é arquitetural, aproximando-se do trompe-l'oeil barroco, das pinturas de tetos que confundem pintura e arquitetura, onde "em muitos casos, deveremos, por exemplo, nos perguntar onde começa o quadro-objeto e onde termina o entorno, arquitetural, notadamente, da obra" ${ }^{10}$. A moldura é como um quadro-objeto que rodeia a obra e fabrica um entorno ${ }^{11}$.

No Panorama, Victor Meirelles procurava ambientar o espectador dentro de um espaço aparentemente sem molduras e limite horizontal. Estar envolvido pela paisagem exigia outra forma de composição e organização da pintura. $\mathrm{Na}$ 
Primeira Missa, no ponto culminante do evento, Frei Henrique levanta as mãos para o céu, celebrando o momento da consagração, da reflexão e do silêncio. No Panorama a ação precisa de alguns cuidados para não ressaltar a imobilidade. $\mathrm{O}$ espectador ficava imerso na paisagem e a cena histórica se apequenava diante da natureza. Para Maria Aparecida Ribeiro:

É certo que com a passagem a panorama, a cena deixou de estar concentrada na missa, pois ganhou um enquadramento paisagístico mais amplo que divide com ela a atenção do espectador. Mas também é verdade que a paisagem acrescentada, composta de águas, acaba por acentuar o ermo onde se dá a celebração e por reforçar o sentido de que à expansão do Império estava vinculada a da fé cristã. ${ }^{12}$

Nos dois casos o artista precisa condensar o acontecimento numa única imagem, num espaço reduzido. $\mathrm{O}$ evento tem que ser contado através de uma cena apenas, de uma imagem congelada, o momento mais representativo da narração. Na pintura histórica, o instante escolhido tem que estar centrado num foco e Meireles "escolheu o momento mais solene da Eucaristia, a Consagração (do vinho), para fixar na tela. A elevação do cálice e a cruz dirigem para o alto o olhar do observador", sendo que há uma luz incidente no altar e zona central que contrasta "com a sombra em que estão colocados, sobretudo os índios, a indicar que o olhar do pintor privilegia a celebração" ${ }^{13}$.

Cruz e espada são um dois elementos geométricos que organizam o centro triangular da cena. A dominação dos portugueses instaura-se pela cruz e pela espada. Em ambos os casos, o sangue é o elemento de união, simbolizado no cálice erguido pelo Frei Henrique na consagração e no manto vermelho de Pedro Álvares Cabral. A cabeça de Cabral é o ápice deste triângulo, no centro da composição formada pela cruz sobre o baú e a espada do português encapuzado ajoelhado. A cruz que catequiza e a espada que subjuga. A forma da força e a forma da fé se equivalendo e celebrando a morte. A cena central da missa, com a imensa cruz de madeira, é límpida, clara, transparente, silenciosa.

A centralidade da composição destaca a cena principal através de linhas diagonais, cor e, principalmente, as profundidades que conduzem o olhar através das distâncias e onde o Monte Pascoal é um detalhe organizador: "Meirelles quer a cena principal mais ao longe, integrando-a numa suavidade atmosférica, num clima espiritualizado"14. Entre as características de composição, o vertical e o horizontal onde "a cruz de Meirelles, longilínea, traça o eixo condutor que leva o olhar para o alto, enquanto o horizonte abre-se no fundo como um instrumento da serenidade (...) desenrola com calma seu episódio numa horizontalidade um pouco onírica" ${ }^{15}$. 
Victor Meirelles tinha uma composição minuciosa, precisa, um fazer artístico paciente, elaborado, meticuloso. Era um pintor detido nos detalhes, na pesquisa, na composição. O índio na árvore contempla atentamente toda a cena de um lugar privilegiado: ele está no alto de uma árvore. Ele tem o ponto de vista da visão panorâmica. Ele é o que está mais próximo do espectador do Panorama de 1900 e do olhar do próprio pintor com a visão do conjunto da cena principal, do mar e das caravelas.

A Primeira Missa no Brasil tem uma trilha de índios sobre o caminho de poeira do lado esquerdo da tela, que geralmente fica esquecido. São os índios que estão chegando ao final da missa, vindos de um interior empoeirado, barrento, tropical. Nesta margem esquerda, o detalhe são os índios que parecem estar chegando por uma longa trilha empoeirada. Eles vêm quase numa algazarra, estupefatos, admirados, assustados, em uma grande multidão. Passam como se estivessem dando a volta e soubessem por onde entrar na cena. A trilha thes era conhecida, mas não o cenário montado pelos portugueses. Os índios demonstram sua diversidade enquanto os portugueses estão concentrados num objetivo. E é exatamente este grupo a "cantar e dançar", referida por Ribeiro que chama mais a atenção, contradizendo em parte Pêro Vaz de Caminha, que disse estarem os índios de "tal maneira assossegados" que causavam devoção aos portugueses. Segundo Ribeiro:

\begin{abstract}
A adoração dos portugueses contrasta com as diferentes posturas dos nativos, embora quase todos estes pareçam reagir de forma positiva à liturgia: um sobe na árvore; outros, por trás do altar, parecem cantar e dançar; outros, ainda, sentados pelo chão, como a índia que amamenta um curumim, não deixam de observar aquele desconhecido ritual ${ }^{16}$.
\end{abstract}

O alvoroço que Meirelles pinta do grupo de índios à esquerda, expressa a dança e o canto. Este grupo que passa às costas dos portugueses é um contraponto aos índios do primeiro plano, contemplativos, sombreados, sossegados, citados por Pêro Vaz de Caminha: "eles se puseram todos assim, como nós estávamos, com as mãos levantadas; e de tal maneira sossegados que certifico a Vossa Alteza que nos fez muita devoção. Estiveram assim conosco até acabada a comunhão" ${ }^{17}$.

Os índios que chegam depois, no decorrer da missa, parecem não ter a noção de tempo, são selvagens. Neste caminho pode-se perceber a poeira suspensa impregnando os corpos. Estes índios chegam fora de hora, fora de ordem. Os sacerdotes de costas para este caminho, e os outros portugueses olhando para o chão e meditando não se perturbam com a cena destes índios, é como se a presença deles não fosse uma surpresa, assim como é a missa para os índios. O 
caminho dos índios é anárquico, barulhento, desorganizado, coletivo. Um caos em contraposição à ordem religiosa e militar européia. A presença desta poeira na obra nos dá indícios que nem tudo está resolvido, nem tudo está em ordem, nem tudo será pacífico. Este caminho empoeirado pode estar evidenciando os elementos de resistência, de um desvio da norma, de algo que não está acomodado. Os índios da esquerda, embrenhados na mata, irrompem no silêncio da cerimônia, sem parecer saber do que se trata. A missa é um espetáculo contemplativo que exige um conhecimento prévio para perceber o momento da consagração, a celebração da vida sobre a morte, a corporificação de Cristo no ritual católico.

O índio sobre a árvore - o panoramista e os índios empoeirados são os detalhes da imagem que exatamente são recortados em algumas reproduções da Primeira Missa no Brasil em livros didáticos. Este grupo de índios é suprimido da cena como se não fosse essencial. Há um enquadramento que elimina as partes supérfluas optando-se por resumir tudo à cena principal, esquecendo-se do resto, das margens que a circundam. Estes cortes aparentemente não alteram a leitura da obra como documento. Tudo isto parece ser feito com muita naturalidade, reforçado por um discurso que reforça o tema principal ${ }^{18}$. Além disto, a alteração da imagem acabou acentuando ainda mais a verticalidade da cruz e não a horizontalidade da cena.

Poucos anos depois da Primeira Missa no Brasil, Victor Meirelles pintou Moema, inspiração romântica no poema épico Caramuru (1781), de frei José de Santa Rita Durão (1722-1784). Moema é a figura baudelairiana com "a cor acobreada capaz de acionar um erotismo baseado no estranhamento. Nela o pressuposto do navio que se vai. Nela, ainda, a dádiva do corpo magnífico que é quase cadáver, o repouso e a morte entrecruzados" 19 . O índio não era mais aquele hospedeiro que "acolhe o irmão europeu e aceita a doutrina bíblica como um hino que vem suavizar-lhe o destino"20. Este hino suavizante não coincidia com a imagem mórbida de Moema em "adiantado estado de putrefação" 21 . Este momento é o da visão posterior ao paraíso. O olhar da desilusão, do inconsolável, da morte certa e das ruínas.

Recebido em 18 de junho de 2008

\section{NOTAS}

I O Argos, Nossa Senhora do Desterro, 30 de ago. 1861, n.770.

2 Sobre este tema ver FRANZ, Teresinha Sueli. Educação para uma compreensão crítica da arte. Prefácio de Fernando Hernández. Florianópolis: Letras contemporâneas, 2003; RIBEIRO, Maria Aparecida. A carta de Caminha e seus ecos: estudo e antologia. Coimbra: Ângelus Novus, 2003. 


\footnotetext{
${ }^{3}$ Manuel Araújo Porto Alegre sugeriu este tema a Victor Meirelles no qual poderia realizar sua primeira grande obra. Ele foi o primeiro diretor brasileiro da Academia Imperial das Belas Artes (entre 1854 e 1857) e principal mentor de Meirelles durante sua viagem à Europa, orientando os rumos de seu trabalho através de correspondência.

${ }^{4} \mathrm{COLI}$, Jorge. Primeira missa e invenção da descoberta. In: NOVAES, Adauto (Org.). A descoberta do homem e do mundo. São Paulo: Companhia das Letras, 1998, p. 107.

${ }^{5}$ PAIVA, Eduardo França. História \& imagens. Belo Horizonte: Autêntica, 2002, p. 92 (Coleção História \& Reflexões; I).

${ }^{6}$ BORDINI, Silvia. Sans frontières. La peinture des Panoramas entre vision et participation. In: Les arts de I' hallucination. Sous la direction de Donata Pesenti Campagnoni et Paolo Tortonese. Paris: Presses de la Sorbonne Nouvelle, 200I, p.76.

7 Ver DAMISCH, Hubert. A astúcia do quadro. Gávea: Revista de arte e arquitetura, PUC. Rio de Janeiro, n. I0, mar. de 1993.

${ }^{8}$ AUMONT, Jacques. O olho interminável. Tradução de Eloisa Araújo Ribeiro. Apresentação de Rubens Machado Jr. São Paulo: Cosac \& Naify, 2004 (Coleção Cinema, teatro e modernidade), p. I I 3.

9 SIMMEL, Georg. Le cadre: um essai esthétique. In: SIMMEL, Georg. Le cadre et autres essais. Traduit et préfacé par Karine Winkelvoss. Paris: Éditions Gallimard, 2003, p.35.

${ }^{10}$ AUMONT, Jacques. Op.cit., p. II 2.

"Idem, ibidem.

12 RIBEIRO, Maria Aparecida. A carta de Caminha e seus ecos: estudo e antologia. Coimbra: Ângelus Novus, 2003, p.42-43.

13 Idem, p. 40.

${ }^{14} \mathrm{COLI}$, Jorge. Primeira missa e invenção da descoberta. In: NOVAES, Adauto (Org.). A descoberta do homem e do mundo. São Paulo: Companhia das Letras, 1998, p. II 3.

${ }^{15}$ Idem, p. II 4.

${ }^{16}$ RIBEIRO, Maria Aparecida. A carta de Caminha e seus ecos: estudos e antologia, p.40.

${ }_{17}$ CAMINHA, Pero Vaz de. Carta: ao rei Dom Manuel. Porto Alegre: Mercado Aberto, 1999, p.56.

${ }_{18}$ Entre outros, no livro organizado por Adauto Novaes, A descoberta do Homem e do Mundo, a imagem da Primeira Missa é fragmentada, omitindo-se os indígenas na árvore. No livro de Eduardo Bueno, Brasil: uma história, as duas margens da pintura são suprimidas, assim como o grupo de índios no caminho empoeirado da esquerda, no livro As barbas do imperador, de Lilia Moritz Schwarcz. Escrevendo sobre representações indígenas, entre elas, as imagens de Moema e a Primeira Missa no Brasil, Schwarcz, na página 147, se refere aos índios como figurantes contemplativos: "Nesses quadros, os indígenas passivos e idealizados compõem a cena sem alterá-la fundamentalmente: são quase um elemento colado à paisagem tropical".

${ }^{19} \mathrm{COLI}$, Jorge. A Batalha de Guararapes de Victor Meirelles e suas relações com a pintura internacional. Campinas: IFCH-UNICAMP, 1994 (Tese de Livre Docência), p.319.

20 MILHOMEM, Wolney. O humanista Vítor Meireles. Porto Alegre: Edições Flama, 1972, p. 44.

2' SAMPAIO, João Zeferino Rangel de. O quadro da Batalha dos Guararapes, seu autor e seus críticos. Rio de Janeiro: Typographia de Serafim José Alves, I880, p.98.
} 